\title{
PEMETAAN KERAWANAN BENCANA GEMPA BUMI DENGAN METODE PSHA PERIODE ULANG 2500 TAHUN STUDI KASUS PULAU LOMBOK - NUSA TENGGARA BARAT
}

\author{
Sugeng Kurniawan, Dwa Desa Warnana, Juan Pandu G. N. R.
}

Departemen Teknik Geofisika, Fakultas Teknik Sipil Lingkungan dan Kebumian, Institut Teknologi Sepuluh Nopember e-mail : sugeng199@gmail.com

\begin{abstract}
Abstrak. Pulau Lombok terletak pada sistem trench Jawa-Sumba yang meliputi sistem trench Sunda selatan Sumba, Sumbawa, Lombok, Bali dan Jawa. Pulau ini memiliki bahaya kerentanan seismik yang cukup tinggi dengan adanya dua sumber gempa utama yaitu Flores Back-arc Thrust dan subduksi Lempeng Indo - Australia. Karena perlu dibuat peta kerentanan seismik untuk Pulau Lombok dengan metode PSHA berupa nilai PGA dan mengetahui seberapa jauh efek sumber gempa tersebut terhadap Pulau Lombok. Penelitian dimulai dengan melakukan analisa sumber gempa pada daerah penelitian dan pengumpulan data katalog gempa. Data katalog gempa kemudian dilakukan konversi magnitudo ke Mw (magnitude moment), lalu dilakukan de-clustering untuk mendapatkan gempa utama. Lalu mencari nilai $a \& b$ value untuk sumber gempa background. Hasil dari analisis sumber gempa adalah digitasi titik atau lokasi dari sumber gempa (patahan \& subduksi) yang berupa koordinat, kemudian dilakukan pemilihan fungsi atenuasi sesuai karakteristik sumber gempa yang merujuk pada buku PUSGEN 2017. Data $a$ \& $b$ value untuk setiap sumber, fungsi atenuasi, dan data koordinat sumber gempa dibawa ke tahapan PSHA yang hasilnya adalah nilai percepatan spectral untuk setiap grid yang telah ditentukan pada periode ulang tahun tertentu. Dari hasil pengolahan didapatkan nilai PGA T=0s adalah $0.35-0.605 \mathrm{~g}$, untuk nilai PGA $\mathrm{T}=0.2 \mathrm{~s}$ adalah $0.85-1.5 \mathrm{~g}$ dan untuk nilai PGA T=1s adalah $0.425-0.68 \mathrm{~g}$. Efek PGA terbesar dipengaruhi oleh efek subduksi lalu patahan dan terakhir akibat gempa background.
\end{abstract}

Kata Kunci: PGA; PSHA; Pulau Lombok.

\begin{abstract}
The island of Lombok is located on the Java-Sumba trench system which includes the Sunda trench system south of Sumba, Sumbawa, Lombok, Bali and Java. This island has a high seismic hazard with 2 main earthquake sources, there is Flores Back-arc Thrust and subduction of Indo-Australian Plate. Because it needs to be made a seismic vulnerability map for Lombok Island with the PSHA method in the form of PGA values and knowing how far the effect of the source of the earthquake on the island of Lombok. The study began with analyzing earthquake sources in the study area and collecting earthquake catalog data. The earthquake catalog data have to converted to Mw (magnitude moment), then declustering to get the main earthquake. Then look for the $a \& b$ value for the background earthquake source. The results of the earthquake source analysis are digit digitization or location of the earthquake source (fault \& subduction) in the form of coordinates, then the attenuation function is selected according to the earthquake source characteristics that refer to the PUSGEN 2017. Book data $a \& b$ value for each source, attenuation function, and the earthquake source coordinate data is taken to the PSHA stage, the result of which is the spectral acceleration value for each predetermined grid in a particular birthday period. From the results of processing, the value of PGA $T=0$ s is $0.35-0.605 \mathrm{~g}$, for $P G A$ value $T=0.2 \mathrm{~s}$ is $0.85-1.5 \mathrm{~g}$ and then for the PGA T value $=1 \mathrm{~s}$ is $0.425-0.68 \mathrm{~g}$. The biggest PGA effect is influenced by the subduction effect and then the fracture and finally by earthquake background effect.
\end{abstract}

Keywords: PGA; PSHA; Lombok Island.

\section{PENDAHULUAN}

Pulau Lombok terletak di Provinsi Nusa Tenggara Barat, Pulau Lombok termasuk kedalam gugusan pulau di sebelah timur Pulau Jawa yang membentang dari Pulau Bali hingga Pulau Timor. Pulau yang memiliki jumlah penduduk sekitar $\pm 3,4$ juta jiwa (BPS, 2014) ini memiliki tingkat bahaya seismisitas yang cukup tinggi dengan adanya subduksi Lempeng Indo - Australia di selatan Pulau Lombok dan Flores Back-arc Thrust di utara Pulau Lombok, perlu dibuat peta kerawanan gempa (Seismic Hazard) yang dibuat dengan dengan menganalisa nilai percepatan tanah atau Peak Ground Acceleration (PGA). Terdapat dua metode yang dapat digunakan untuk pembuatan seismic hazard yaitu Deterministic Seismic Hazard Analysis 
(DSHA) \& Probabilistic Seismic Hazard Analysis (PSHA) (Sieh dan Natawidjaja, 2002).

Penelitian ini dilakukan dengan metode PSHA. PSHA merupakan teknik yang menganalisa kejadian gempa untuk periode ulang tahun tertentu dengan membuat kemungkinan (atau probabilitas) dari berbagai tingkat gerakan tanah di suatu tempat (atau peta tempat) dengan diberikan berbagai skenario kemungkinan terjadinya gempa bumi.

\section{Geologi Regional}

Keadaan geologi wilayah NTB didominasi oleh batuan gunung api serta aluvium (resent). Batuan tertua berumur tersier sedangkan yang termuda berumur kuarter. Batuan tersier di Pulau Lombok terdiri dari perselingan batu pasir kuarsa, batu lempung, breksi, lava, tufa dengan lensa-lensa batu gamping, batu gamping, dan dasit. Batuan kuarter di Pulau Lombok terdiri dari perselingan breksi gampingan dan lava, breksi, lava, tufa, batu apung, dan breksi lahar. Batuan kuarter di Pulau Sumbawa terdiri dari terumbu koral terangkat, epiklastik (konglomerat), hasil gunung api tanah merah, gunung api tua, gunung api Sangiang, gunungapi Tambora, gunung api muda dan batu gamping koral. Aluvium dan endapan pantai cukup luas terdapat di Pulau Sumbawa dan Lombok (Pemerintah Provinsi NTB, 2013).

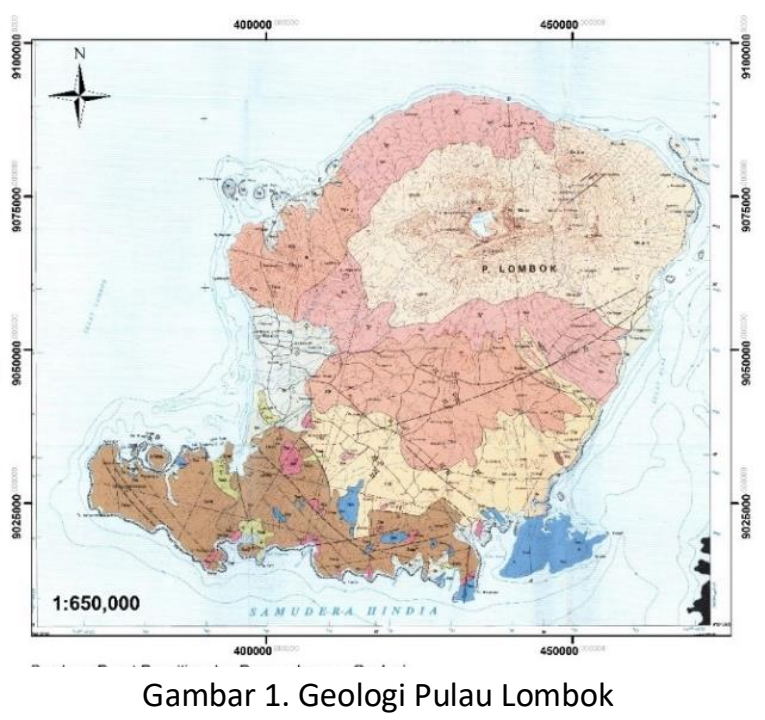

\section{Peak Ground Acceleration (PGA)}

Percepatan tanah maksimum dinyatakan dalam $g$ (Gravitational Acceleration $=\mathrm{g}$ ) atau $\mathrm{m} / \mathrm{s}^{2}(1 \mathrm{~g}=$ $9,81 \mathrm{~m} / \mathrm{s}^{2}$ atau dalam gal dimana 1 gal sama dengan $\left.0,01 \mathrm{~m} / \mathrm{s}^{2} 1 \mathrm{~g}=981 \mathrm{Gal}\right)$. Nilai percepatan tanah maksimum yang dihasilkan menunjukkan tingkat resiko bencana yang terjadi. Nilainya dapat digunakan sebagai bahan pertimbangan mitigasi bencana, desain struktur bangunan dan rencana tata ruang. Karena kondisi kompleks yang mempengaruhi PGA gempabumi berkekuatan sama dapat memberikan hasil yang berbeda dengan banyak gempabumi berkekuatan moderat menghasilkan nilai PGA signifikan lebih besar dari gempa berkekuatan besar (Irwansyah dan Winarko, 2012).

\section{Probabilistic Seismic Hazard Analysis (PSHA)}

Metode PSHA secara umum berkerja dengan memperhatikan sumber event gempa disertai dengan data historikal kegempaan lalu di hitung dengan Ground Motion Prediction equation (GMPe) Metode PSHA dipilih karena memiliki keunggulan dapat memprediksi kejadian gempa hingga ribuan tahun kedepan bergantung pada kelengkapan data yang dimilikinya dan kekurangan dari metode ini ialah banyaknya asumsi atau ketidakpastian yang timbul dalam melakukan analisis sehingga diperlukan parameter kontrol atau acuan (Baker, 2008).

$$
\begin{aligned}
& P(I M>x)= \\
& \int_{m_{\min }}^{m_{\max }} \int_{0}^{r_{\max }} P(I M>x \mid m, r) f_{M}(m) f_{R}(r) d r d m
\end{aligned}
$$

\section{METODOLOGI}

Penelitian dimulai dengan melakukan analisa sumber gempa pada daerah penelitian dan pengumpulan data katalog gempa. Data katalog gempa kemudian dilakukan konversi magnitudo ke Mw (magnitude moment), lalu dilakukan declustering untuk mendapatkan gempa utama. Lalu mencari nilai $a \& b$ value untuk sumber gempa background. Hasil dari analisis sumber gempa adalah digitasi titik atau lokasi dari sumber gempa (patahan \& subduksi) yang berupa koordinat, kemudian dilakukan pemilihan fungsi atenuasi sesuai karakteristik sumber gempa yang merujuk pada buku PUSGEN 2017. Data $a \& b$ value untuk setiap sumber, fungsi atenuasi, dan data koordinat sumber gempa dibawa ke tahapan PSHA yang hasilnya adalah nilai percepatan spektral untuk setiap grid yang telah ditentukan pada periode ulang tahun tertentu. 


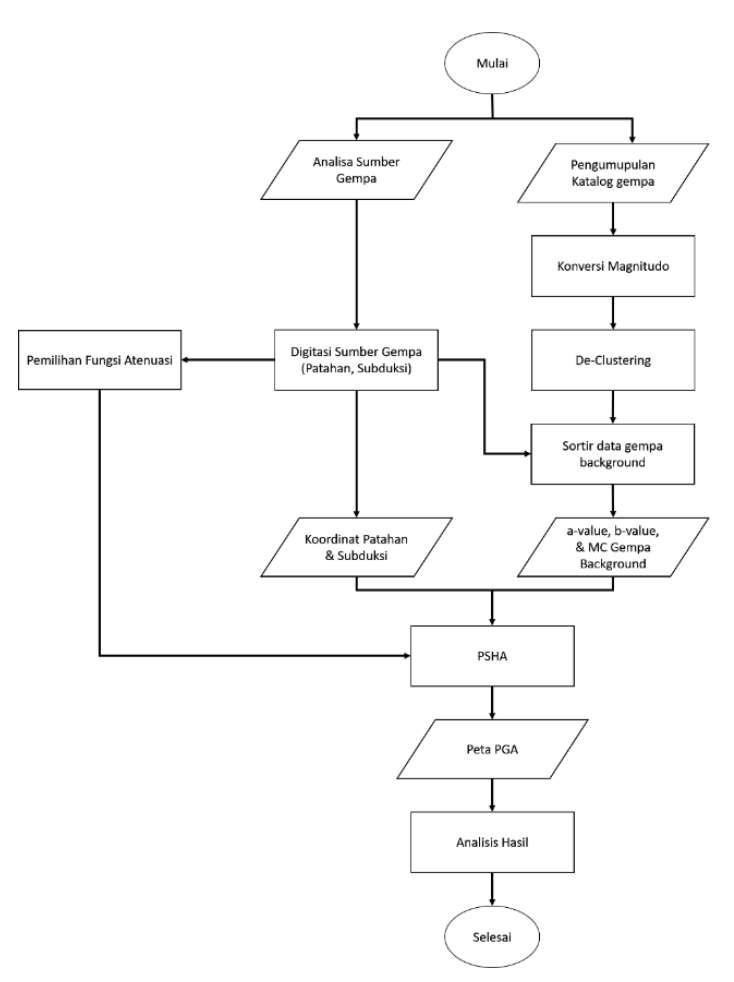

Gambar 2. Alur Penelitian

\section{HASIL DAN PEMBAHASAN}

Pada hasil pengolahan penelitian ini diperoleh peta persebaran PGA batuan dasar sebagai berikut :

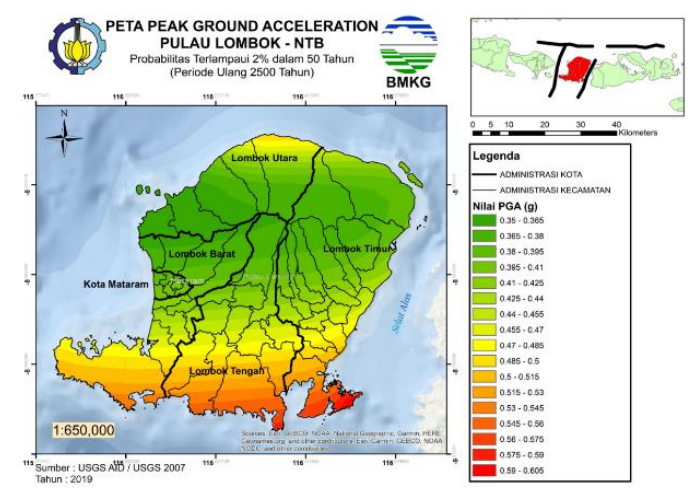

Gambar 3. PGA (T=0s) 2\% untuk 50 tahun masa bangunan

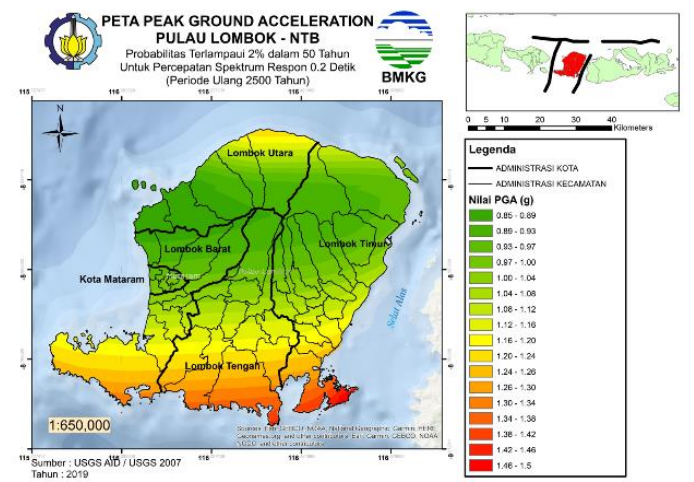

Gambar 4. PGA (T=0.2s) 2\% untuk 50 tahun masa bangunan

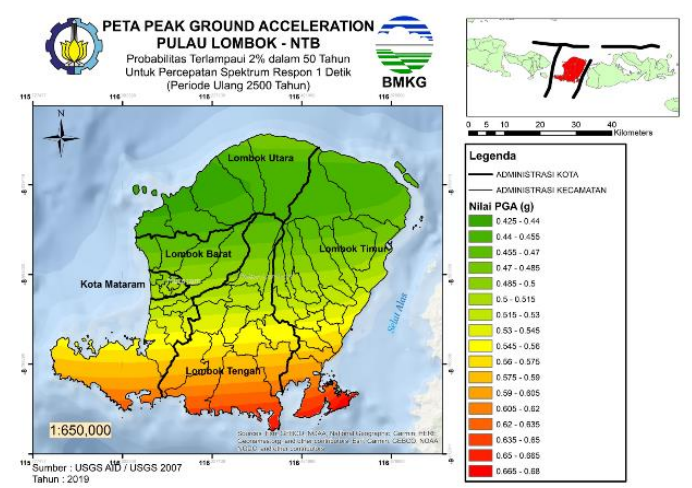

Gambar 5. PGA (T=1s) 2\% untuk 50 tahun masa bangunan

Nilai PGA yang diperoleh merupakan PGA batuan dasar (bedrock) dengan periode $\mathrm{T}=0 \mathrm{~s}, \mathrm{~T}=0.2 \mathrm{~s}$ untuk periode pendek, dan $\mathrm{T}=1 \mathrm{~s}$ untuk periode panjang. Dimana setiap periode percepatan mewakili periode getar struktur untuk masingmasing tingkatan. Misal, pada periode 0 detik, maka akan cukup berpengaruh pada getaran pondasi bagunan. Kemudan periode 0,2 detik cukup mewakili periode getar struktur terpendek (bangunan 2 tingkat). Sedangkan periode panjang 1,0 detik akan berpengaruh pada guncangan di gedung bertingkat hingga 10 lantai. Sehingga jika bangunan gedung tersebut berdiri pada wilayah dengan nilai percepatan tanah di permukaan yang cukup tinggi serta memiliki periode alami struktur yang sama dengan periode gempa, maka dapat dipastikan terjadi amplifikasi dan resonansi yang menyebabkan gedung tersebut kemungkinan mengalami simpangan dan terancam runtuh (BSN, 2012).

Perolehan nilai PGA yang didapat pada hasil peta diatas yaitu, untuk periode ulang 500 tahun $\mathrm{T}=0 \mathrm{~s}$ adalah $0.35-0.605 \mathrm{~g}$, untuk $\mathrm{T}=0.2 \mathrm{~s}$ adalah 0.85 $-1.5 \mathrm{~g}$ dan untuk $\mathrm{T}=1 \mathrm{~s}$ adalah $0.425-0.68 \mathrm{~g}$. Terlihat sebuah trend pada gambar 3, 4 dan 5 dengan 
persebaran nilai PGA, dimana terlihat bahwa efek subduksi Sumba pada bagian selatan dan efek patahan Flores Back-arc Thrust pada bagian utara mendominasi, sedangkan pada efek gempa background tidak terlihat secara signifikan. Nilai PGA pada $\mathrm{T}=0 \mathrm{~s}$ akan mengalami peningkatan di $\mathrm{T}=0.2 \mathrm{~s}$ hal ini dikarenakan gelombang mengalami proses amplifikasi sehingga nilai PGA meningkat, dari $\mathrm{T}=0.2 \mathrm{~s}$ ke $\mathrm{T}=1 \mathrm{~s}$ terjadi penurunan nilai $\mathrm{PGA}$ akibat proses atenuasi seiring dengan bertambahnya jarak.

Wilayah Lombok bagian tengah merupakan daerah yang relatif aman dari bahaya seismisitas akibat efek patahan Flores Back-arc Thrust dan subduksi Sumba

\section{PENUTUP}

\section{Simpulan}

Kesimpulan yang dapat diambil pada penelitian kali ini adalah :

1. Nilai PGA batuan dasar untuk $\mathrm{T}=0 \mathrm{~s} \mathrm{~T}=0 \mathrm{~s}$ adalah $0.35-0.605 \mathrm{~g}$, untuk $\mathrm{T}=0.2 \mathrm{~s}$ adalah $0.85-1.5 \mathrm{~g}$ dan untuk $\mathrm{T}=1 \mathrm{~s}$ adalah $0.425-0.68 \mathrm{~g}$

2. Efek Subduksi Sumba pada bagian selatan dan efek patahan Flores Back-arc Thrust pada bagian utara memiliki kontribusi terbesar pada hasil persebaran nilai PGA, sehingga meningkatkan bahaya seismistas pada bagian selatan dan utara Pulau Lombok

3. Wilayah Lombok bagian tengah memiliki potensi bahaya gempa yang relatif kecil (aman).

\section{Saran}

Pada penelitian selanjutnya dapat dilanjutkan untuk mencari PGA permukaan (Surface) atau Pseudo Spectral Acceleration (PSA) dan menggunakan fungsi atenuasi terbaru

\section{Ucapan Terima Kasih}

Penulis mengucapkan terima kasih kepada sub bidang Layanan Informasi Seismologi Teknik BMKG Jakarta Pusat yang telah memberi kesempatan kepada penulis untuk melakukan penelitian dan pengolahan PSHA untuk studi kasus Pulau Lombok, Nusa Tenggara Barat.

\section{DAFTAR PUSTAKA}

Baker, J. (2008), An Introduction to Probabilistic Seismic Hazard Analysis (PSHA),

BPS (2014), Badan Pusat Statistik Provinsi Nusa Tenggara Barat. Diambil 24 Januari 2020, dari https://ntb.bps.go.id/statictable/2015/11/10/1 54/jumlah-penduduk-dan-rasio-jenis-kelaminmenurut-kabupaten-kota-2014.html.

BSN (2012), SNI 1726: 2012 Tata Cara Perencanaan Ketahanan Gempa untuk Struktur Bangunan Gedung dan Non Gedung, SNI 1726, Badan Standardisasi Nasional, Jakarta.

Irwansyah, E. dan Winarko, E. (2012), "ZONASI DAERAH BAHAYA KEGEMPAAN DENGAN PENDEKATAN PEAK GROUND ACCELERATION (PGA)", Seminar Nasional Informatika (SEMNASIF), Vol.1, No.5. Diambil dari http://www.jurnal.upnyk.ac.id/index.php/semn asif/article/view/1123.

Pemerintah Provinsi NTB (2013), Rencana Pembangunan Jangka Menengah Daerah Provinsi Nusa Tenggara Barat Pemerintah Provinsi NTB,

Sieh, K. dan Natawidjaja, D. (2002), "Neotectonics of the Sumatran Fault, Indonesia", Journal of Geophysical Research: Solid Earth, Vol.105, No.B12, hal. 28295-28326. http://doi.org/10.1029/2000JB900120. 